\title{
Long-term food-exposure of zebrafish to PCB mixtures mimicking some environmental situations induces ovary pathology and impairs reproduction ability
}

\author{
Tarek Daouk $^{\mathrm{a}, \mathrm{b}}$, Thibaut Larcher ${ }^{\mathrm{c}}$, François Roupsard ${ }^{\mathrm{d}}$, Laura Lyphout ${ }^{\mathrm{a}}$, Cyril Rigaud ${ }^{\mathrm{a}, 1}$, \\ Mireille Ledevin ${ }^{c}$, Véronique Loizeau ${ }^{\mathrm{d}}$, Xavier Cousin $^{\mathrm{a}, \mathrm{b}, \mathrm{e}, *}$
}

a IFREMER L'Houmeau, Place Gaby Coll, BP7, 17137 L'Houmeau, France

b Fédération de Recherche en Environnement pour le Développement Durable, FR-3097, Université de La Rochelle, CNRS, IFREMER, 2 rue Olympe de Gouges, 17000 La Rochelle, France

c INRA, APEX, UMR703, Oniris, 44307 Nantes, France

d IFREMER Laboratoire de Biogéochimie des Contaminants Organiques, Centre de Brest, BP70, 29280 Plouzané, France

INRA SCRIBE, Campus de Beaulieu, 35042 Rennes, France

${ }^{1}$ Present address: Institut Maurice-Lamontagne, C.P. 1000, 850 Route de la Mer, Mont-Joli (QC) G5H 3Z4, Canada.

*: Corresponding author : Xavier Cousin, Tel.: +33 546500621 ; fax: +33 546500600 ;
email address : mailto:xavier.cousin@ifremer.fr

\begin{abstract}
:
Although the use of polychlorinated biphenyls (PCBs) has been banned for several decades, they are still present in the environment and are occasionally mechanically released from sediment or transferred through the trophic chain. Field analyses have established correlations between exposure to PCBs and alterations in fish physiology including reproductive function. Experimental exposures have been mainly performed using dioxin-like PCBs or other congeners at very high concentrations. However, these studies are often difficult to relate to real-life conditions. In the present study, we performed a life-cycle exposure using zebrafish model and mixtures representative of some environmental situations in terms of doses, composition and containing mainly non dioxinlike congeners. Exposure was performed through diet which is the main contamination route in the field. We demonstrated a bioaccumulation of PCBs in males and females as well as a maternal transfer to the eggs. Survival, growth and organ size were similar for all conditions. Several reproductive traits were altered after exposure to a PCB-contaminated diet, including a reduction in the number of fertilized eggs per spawn as well as an increase of the number of poorly fertilized spawns. This latter observation was found irrespective of the sex of contaminated fish. This is related to modifications of ovary histology revealing a decrease of maturing follicles and an increase of atretic follicles in the ovaries of females exposed to PCBs. These results indicate that exposure to PCBs mixtures mimicking some environmental situations, including mainly non dioxin-like congeners, can lead to a dramatic reduction in the number of offspring produced by a female over a lifetime. This is of great concern for wild species living under natural conditions.
\end{abstract}

\section{Highlights}

Zebrafish lifecycle exposure to PCBs mixture with low content in dioxin-like congeners. PCBs bioaccumulation in adults and transfer to eggs. Reduction of fertilization rate due to an increase in poorly fertilized spawn number. Fertilization rate decreases is observed regardless of the sex of the contaminated fish. Reduction of the proportion of maturing follicles and increase of atresia.

Keywords: Zebrafish ; PCBs ; Chronic exposure ; Physiology ; Reproduction ; Atresia 


\section{Introduction}

Polychlorinated biphenyls (PCBs) are synthetic chlorinated aromatic hydrocarbons that are non-flammable, hydrophobic, and chemically stable. In the 80 's, when PCBs were banned, global production was estimated to be over 1.5 million tons (Breivik et al., 2002). Because of their extensive industrial use and chemical stability, PCBs have accumulated in the environment and biota. Their high lipophilicity and environmental stability has allowed them to persist in the environment for long periods resulting in a wide geographical distribution. In the environment, PCBs are buried in sediments and particles can be released by, for example, trawling, dredging or floods. This explains why biota can still be contaminated. The long biological half-life and high liposolubility of PCBs can lead to their bioaccumulation and biomagnification along food chains involving a wide range of trophic levels, with a potential risk for high trophic level predators (Borga et al., 2001 ; Fisk et al., 2001 ; Nfon and Cousins, 2006). For human and fish populations, dietary intake, especially the consumption of marine organisms, is considered as one of the most important sources of exposure to PCBs (Johansen et al., 1996 ; Muir et al., 2003 ; Nyman et al., 2002 ; Pompa et al., 2003)

Data collected from fish in the field suggests that PCB could have physiological effects although the consequences of PCB exposure are difficult to ascertain. Some of these effects have been confirmed by laboratory experiments and include progressive weight loss ('wasting syndrome'), alteration of lipid metabolism, hepatotoxicity, immunotoxicity, alteration of endocrine system function and reproduction, teratogenicity and developmental toxicity, and tumor promotion (Foekema et al., 2008 ; Monosson, 1999/2000 ; Ross, 2004 ; Safe, 2005 ; Schell and Gallo, 2010 ; van Ginneken et al., 2009)

The use of fish models to address ecotoxicology issues has become more prevalent in recent years. Small fish models have allowed more detailed investigations of the mechanisms that underlie the adverse effects of pollutant exposure (Hill et al., 2005 ;Hinton et al., 2005 ; Spitsbergen and Kent, 2003). Many publications have reported the effects of exposing zebrafish or medaka to pollutants, particularly PCBs. These studies have investigated pollutant exposure via different routes and at different stages of development from embryo to adult. Alteration of several physiological processes including development, reproduction, and behavior have been demonstrated Billsson et al., 1998 ; Grimes et al., 2008 ; Lyche et al., 2010 ; Na et al., 2009 ; Nakayama et al., 2004 ; Nakayama et al., 2005a ; Nakayama et al., 2005b ; Nourizadeh-Lillabadi et al., 2009 ; Örn et al., 1998 ; Westerlund et al., 2000). However in most of these studies the exposures were performed using individual congeners and or high doses.

In the present study, we have tried to use exposure conditions that resemble as closely as possible those occurring in the wild. For this purpose, juvenile and adult zebrafish were exposed to a mixture of PCBs which were environmentally relevant in terms of dose and composition. To further mimic naturally occurring situations, long-term exposure was performed through diet. The aim of the present study was to evaluate the physiological consequences of lifetime exposure of fish to environmentally relevant PCB mixtures in their diet. The mixtures we used included three mono-ortho substituted congeners which are less coplanar than non-ortho dioxin-like ones and belong to priority group 1B (McFarland and Clarke, 1998) and ten non dioxin-like congeners (priority groups 2 and 3). We monitored the bioaccumulation of PCBs in fish over time and as well as transfer to eggs. In particular, we assessed several key issues for reproduction including spawn size and number, fertilization rate, and gonad histology. 


\section{Material and methods}

\subsection{Fish, exposures, and sampling}

Wild type zebrafish (Danio rerio) were bought at 6 weeks of age from a provider dedicated to breeding zebrafish especially for ecotoxicology experiments (Elevage de la grande rivière, Calluire, France). Exposure began 2 weeks later. These fish were maintained and exposed to a PCBs mixture in Ifremer research station L'Houmeau France, under standard conditions: water and room temperature were kept between $26-28^{\circ} \mathrm{C}$ and the photoperiod was $10 \mathrm{~h}$ dark and $14 \mathrm{~h}$ light. Water was obtained after a mix of reverse osmosis treated water and tap water, both being filtered beforehand with dust and charcoal filters, to obtain a $\mathrm{pH}$ of $7.5 \pm$ 0.5 and a conductivity of $300 \pm 50 \mu \mathrm{S} / \mathrm{cm}$. Ammonia, nitrites, and nitrates were monitored daily for 2 months then weekly and remained within recommended ranges (Lawrence, 2007). The fish were raised in a flow-through system made of 20 identical $10 \mathrm{~L}$ tanks in a rack. Water was automatically changed every hour leading to an exchange rate of $4 \mathrm{~L} /$ day/tank. Contaminated water was collected and treated with activated charcoal before being discharged in a sewer. This study was conducted under the approval of the Animal Care Committee of France under the official licence of M.L. Bégout (17-010).

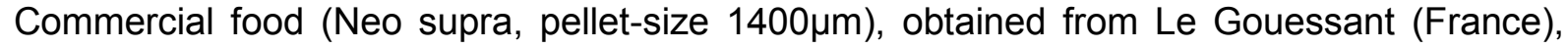
consisted of a formulated feed containing $58 \%$ crude protein and $13 \%$ crude fat. Spiked food was prepared by batch to avoid deterioration and by slowly adding a solution in iso-octane of known amounts of thirteen congeners, (AccuStandard Inc., New Haven, USA, purity above $98 \%$ ) to food pellets in order to prepare diets. PCBs mixtures are composed of the seven indicator PCB congeners (CB28, 52, 101, 118, 138, 153, 180), and a few others to describe a larger range of chlorination from 3 to 8 chlorine atoms (CB105, 132, 149, 156, 170, 194). The latter compounds were chosen because they can highlight any underlying mechanisms acting on the distribution of organic contaminants in biota i.e. bioaccumulation or biotransformation.

CB153 is not metabolized and is used as a representative of all thirteen congeners and therefore only its concentration is reported here. Two diets were prepared: PCB-Medium and PCB-High for which targeted concentrations of individual congeners are shown in Table 1. These concentrations correspond to the one monitored in respectively medium and highly contaminated sites (respectively Loire and Seine estuaries; data from French coastal chemical contamination survey network - ROCCH). Batches of spiked food were stored in amber containers in a cool, dark place throughout their use (circa 1.5 months). Individual PCB congener concentrations were determined in each batch of spiked food (Table 1). Nonspiked food was also analysed for PCB levels, and concentrations were between $<0.05 \mathrm{ng} / \mathrm{g}$ dry weight $(\mathrm{dw})$ and $3.0 \mathrm{ng} / \mathrm{g} \mathrm{dw}$ (mean value calculated on 5 replicates) depending on the congener. In addition to congeners included to spike the contaminated food, CB 31 (not detected; nd), CB 77 (nd), CB110 (0.75 ng/g dw), CB126 (nd), CB128 (nd), CB187 (nd) nonadded congeners and p,p'DDE (3.50 ng/g dw) were measured with the exception of other molecules. The control food exposed only to solvent is further referred as Solvent whereas the unmodified food is referred to as Plain. We used the Plain food to exemplify potential deviation from untreated situations that could be due to solvent or spiking procedures.

After 2 weeks of acclimation, 30 fish were randomly distributed in each tank respecting an equivalent biomass of $214.1 \pm 2.9 \mathrm{mg}$ (mean \pm SEM) within range [188.3-239.1] corresponding to a coefficient of variation of $5.9 \%$. Diets were then assigned to each tank with all diets represented in each rack shelf with 3 tanks for Plain, 3 tanks for Solvent control, 7 tanks for PCB-Medium, and 7 tanks for PCB-High diets. Fish were fed twice (morning and afternoon) on week days and once with a double dose on weekends. During all of the 
experiments, fish were fed $2 \%$ of their wet weight per day. This ration was updated after each biometry. Contamination lasted for 300 days.

Samples were made during biometries for PCB dosage; one or more fish from each sex and condition were euthanized with a lethal dose of benzocaïne (Sigma) and then stored directly at $-20^{\circ} \mathrm{C}$. In some cases, newly spawned eggs were also conserved at $-20^{\circ} \mathrm{C}$ without any water and these samples were dosed for PCB.

\subsection{Chemical analysis}

PCB analysis was performed according to the protocol described by Bodiguel et al. (2009). Briefly, entire sampled fish were extracted in a hot Soxhlet extraction apparatus (Soxtec) over $1.5 \mathrm{~h}$ with a hexane:acetone mixture (80:20). The amount of extracted fat was determined by gravimetric analysis. Then, two successive clean-ups were performed on the extractible material. First, lipids and co-extractible material were destroyed by adding concentrated sulphuric acid. The cleaned extract was then purified by adsorption chromatography on a Florisil column $\left(16 \% \mathrm{MgO}+84 \% \mathrm{SiO}_{2}\right.$, activated for $1.5 \mathrm{~h}$ at $500^{\circ} \mathrm{C}$, deactivated with $3 \%$ of demineralised water) and eluted with pentane. Finally, PCB congeners were analyzed by gas chromatography with an electron capture detector, on a HP 5890 series II equipped with a CP-Sil19 capillary column (60 m length, internal diameter 0.25 $\mathrm{mm}$, and $0.15 \mu \mathrm{m}$ phase film thickness) following optimized conditions described by (JaouenMadoulet et al., 2000). The system was calibrated within quite a large range using a six-point calibration curve to define the linearity range of our detector (ECD) for all contaminants. The relative precision of the method was checked for this type of sample by analyzing five aliquots of a homogeneous-tissue preparation of fish muscle. The results showed standard deviations of less than $10 \%$ for all congeners, indicating that the method had a satisfactory reproducibility. During analysis of the real samples, analytical blanks were systematically measured for every ten samples. The blank concentrations were always less than the concentrations of the lowest standards of all congeners. Finally, 5 replicates of a reference material, BCR-CRM349 (Cod Liver Oil) were analyzed to determine the accuracy and precision of the method. PCB recoveries varied between 74 and $125 \%$. Furthermore, the RSD values ranged from 4 to $19 \%$, with a mean of $10 \%$ for all PCBs. All of these results were in agreement with certified reference values and published data (Schantz et al., 1993). The laboratory regularly takes part in Quality Assurance of Information for Marine Environmental Monitoring in Europe (QUASIMEME) intercomparison exercises for PCBs in biota and our Z-scores are satisfactory, i.e., between -2 and +2 .

\subsection{Phenotypic analysis}

Survival was monitored each day throughout the entire duration of the experiment.

To track fish growth, total body mass and standard lengths were measured approximately every two weeks and sex was recorded when possible. Fish were anaesthetized for $5 \mathrm{~min}$ in benzocaïne $(50 \mathrm{mg} / \mathrm{l})$ during biometric analyses then released into their tank of origin. Specific growth rates (SGR, \%) were also calculated from growth data according to the equation:

$$
\frac{(\text { Ln [weight date 2] }- \text { Ln [weight date 1]) }}{\text { (time between date } 1 \text { and date } 2 \text { in days) }} * 100
$$

At the end of the experiment, 9 females of each condition were weighed as well as their liver and gonads after dissection to calculate the Liver Somatic Index (LSI) and the Gonad Somatic Index (GSI) as a percentage of the organ weight relative to the total body weight. 
Onset of spawning was determined by placing a spawning box (AquaSchwartz, Germany) within each tank from day 48 until a spawn was found in all of them (i.e. day 141). Fish were then regularly set into pairs in spawning boxes. Reproduction couples were obtained by setting up couples on the evening before spawning using fish coming from the same tank. In some cases, fish from Solvent and PCB 500 tanks were mixed to assess the dependence of fertilization rate on sex. Generally, spawning occurs progressively after a few minutes of light illumination. One hour later, eggs were collected, cleaned, sorted (into fertilized or none fertilized), and counted. From each spawn 100 fertilized eggs were set aside into a $10 \mathrm{~cm}$ diameter Petri dish filled with $30 \mathrm{ml}$ of E3 solution $(5 \mathrm{mM} \mathrm{NaCl}, 0.17 \mathrm{mM} \mathrm{KCl}, 0.33 \mathrm{mM} \mathrm{CaCl}$, $0.33 \mathrm{mM} \mathrm{MgSO}_{4}$ ) at $28^{\circ} \mathrm{C}$. Embryo deaths were recorded each day to calculate the embryosurvival percentage. Embryo survival percentage was calculated in all conditions on starving larvae till their death (12-14 days) according to (Örn et al., 1998).

\subsection{Histopathology evaluation}

A histopathological evaluation was performed on 109 fish (69 females and 40 males). The principles of step sectioning adult zebrafish have already been published (Spitsbergen et al., 2000). Briefly, whole fish carcasses were fixed in $4 \%$ formalin after ventral incision of the abdomen for larger individuals. $24 \mathrm{~h}$ later, scales and fins were carefully removed and samples were dehydrated and embedded in paraffin. Serial sagittal step sections were cut from the left side of the fish. Four step sections from each adult fish were mounted on glass slides, 1 from eye anterior chamber level, 1 from eye posterior chamber level, 1 just medial to the eye, and 1 at the midline. Sections were routinely stained with hematoxylin-eosinsafran (HES). Ovarian and testicular tissue features were quantitatively assessed in a blind manner using a digital camera (Nikon DXM 1200, Champigny, France) linked to imageanalysis software (Nikon Imaging Software). For ovaries, all oocytes present on mid-level section and on sections medial to the eye were counted along their morphological stage using middle magnification (Koç et al., 2008). Atretic oocytes, as assessed by their irregular shape and yolk-envelope disruption, were also counted. Individual frequencies of each type of oocyte and indexes of oocytic apoptosis were calculated using ratio of the total ovarian area. For testis, the total area occupied by differentiated E3 spermatids was measured (Schulz et al., 2010) and a ratio was calculated with total observed testis area on two middle magnification fields.

\subsection{Statistical analysis}

Because data do not follow a normal distribution, continuous data, i.e. weight, eggs numbers, fertilization rates, atretic oocytes numbers were analyzed using the Kruskal-Wallis test with Dunn's post hoc test when appropriate. Proportions, i.e. fertilization rate categorization and follicle-stage proportions were analyzed using chi-square test. In other cases, statistical tests are indicated. Statistical analysis was performed with Statistica 9.0 (StatSoft) or Prism 5.0 (GraphPad). Unless otherwise stated, values are indicated as mean \pm SEM. Significance was set at $p<0.05$.

\section{Results}

\subsection{Fish contamination}

The mixture designed to mimic environmental conditions with the concentration of each congener is presented in Table 1. In Solvent and Plain fish, CB153 concentration ranged from $12 \mathrm{ng} / \mathrm{g} \mathrm{dw}$ at the beginning of the experiment to $40 \mathrm{ng} / \mathrm{g} \mathrm{dw}$ after 230 days of 
exposure. Since concentrations in both control groups showed no significant difference (Paired Student's t-test; $\mathrm{p}>0.05 \mathrm{n}=4$ ), they were all considered together. All congeners administered in spiked food were detected in exposed fish at higher concentrations than in control fish. As shown in Figure 1, linear PCB accumulation kinetics were observed in fish during the first three months of exposure and in a similar manner for males and females. From this time point, CB153 concentration in females became highly variable in the [3511644] $\mathrm{ng} / \mathrm{g}$ range for PCB-Medium exposed females and in the [990-9305] $\mathrm{ng} / \mathrm{g}$ range for PCB-High exposed females. In most cases, females with low CB153 concentrations were sampled immediately after having spawned (open circle in Fig. 1), which suggests that females may expel PCBs through spawning. This hypothesis was confirmed as CB153 concentration in control eggs is less than $0.1 \mathrm{ng} / \mathrm{g}$ fresh weight (fw). For eggs produced by females exposed to PCB-Medium diet, CB153 concentration was $16.0 \pm 0.8 \mathrm{ng} / \mathrm{g} \mathrm{fw}$ and 47.6 $\pm 7.8 \mathrm{ng} / \mathrm{g}$ fw for the PCB-High diet (see Figure 2 for the increases observed in PCB-Medium and PCB-High eggs versus control eggs).

\subsection{Physiological indexes}

Over the 300 days of contamination, we noticed no changes in survival rate between groups (Table 2). During the first 52 days of contamination (3 biometries), fish of both sexes were considered together since sex could not be unequivocally determined for every fish. Afterwards, when all fish were sexed, size and weight were calculated for each sex. Whatever the diet, we observed no differences in growth between groups as ascertained by comparison of final weight, specific growth rate (SGR) or condition index (not shown), which were all unchanged (Table 2). Final weight and SGR displayed a very large inter individual variability.

We determined the LSI and GSI for females in each group and observed no significant differences in any of these variables compared with Solvent fish (Table 3).

\subsection{Reproduction}

Although onset of spawning appears delayed after exposure to PCBs, there were no significant differences between the different conditions $(p=0.769)$. On average, Solvent fish began to spawn at day $73.7 \pm 25.7$, whereas contaminated fish began to spawn at day $93.2 \pm$ 17.5 for PCB-Medium and day 109.8 \pm 14.5 for PCB-High (Table 4).

Embryonic development was assessed throughout the duration of this study. We observed neither modification of embryonic development nor changes in the rate of development. We observed no differences in embryo survival, which was assessed until death of all larvae in absence of feeding (data not shown).

Although there was a trend in reduction of spawn size for PCB-High couples, there is no significant difference in the number of eggs per spawn (Table 4). However, if we consider the numbers of fertilized eggs, we observe a trend for PCB-Medium and a significant reduction for PCB-High with approximately one third less fertilized eggs per spawn compared with control spawn. Surprisingly, the fertilization rate is similar for PCB-Medium and PCB-High around $63 \%$, versus $85 \%$ for Solvent control.

Since we obtained highly fertilized spawn from PCB-High couples, we analyzed in more detail the distribution of fertilization rate for each spawn (Fig. 3). In control fish, most of the spawns were highly fertilized with around $80 \%$ of spawns with a fertilization rate over $80 \%$ and less than $10 \%$ of spawns with a fertilization rate under $40 \%$. Spawns from PCB-Medium or PCB-High couples were mainly characterized by a reduction of highly fertilized spawns (less than 50\%) and an increase of poorly fertilized spawns (around 30\%). 
Crosses performed using Solvent and PCB-High fish showed that the fertilization rate was impaired regardless of the sex of the contaminated fish (Fig. 4A) with the same modification of fertilization rate distribution (Fig. 4B). This indicated that the lowering of fertilization rate following PCB exposure was not due to a particular sex. Surprisingly, no additive effect was observed when two contaminated fish were crossed.

\subsection{Gonad histology and follicle atresia}

Irrespective of the diet, examination of whole male gonads revealed the presence of testis with typical architecture, and normal spermatogenesis as evaluated by histology. A quantitative evaluation of the testicular areas occupied by spermatids revealed no differences between control and exposed fish. Ovaries of one-year old females displayed different features depending on diet. The main tissue alterations were then quantified. Relative frequencies of all four stages of follicles including, pre-vitellogenic stages 1 and 2, vitellogenic and post-vitellogenic, were first assessed. Both PCB-Medium and PCB-High female ovaries were characterized by a trend towards a higher proportion of pre-vitellogenic stage-1 oocytes, albeit not significant. In PCB-High females, there was a highly significant lower proportion of pre-vitellogenic stage 2, vitellogenic and post-vitellogenic stages (Fig. 5). Major alterations of oocytic maturation were observed in 4 out of 10 PCB-High fish with a complete absence of vitellogenic and post-vitellogenic stages. In these cases, ovarian tissue was only composed of pre-vitellogenic stages and interstitial tissue was markedly infiltrated by inflammatory cells, mainly macrophages and lymphocytes (Fig. 6).

Ovaries from PCBs females were also characterized by an increase in the number of atretic follicles. In control fish, the number of atretic follicles per microscopic field (mean \pm SEM) is $1.18 \pm 0.28$ in Nature females and $0.76 \pm 0.23$ in Solvent females. These numbers were tripled in PCB-exposed females to $3.19 \pm 0.54$ for PCB-Medium and $3.70 \pm 0.45$ for PCBHigh (only ovaries with all four stages of follicles could be considered; $p<0.01$ ). The presence of atretic follicles was often associated with a peripheral influx of some macrophages phagocytizing oocytic debris.

\section{Discussion}

In this study, we exposed zebrafish to mixtures of PCBs mimicking some environmental situations (as Loire or Seine estuary) through the diet over 300 days. This long period represents almost half the lifespan of zebrafish under laboratory conditions and includes approximately 200 days of reproduction.

PCBs are very persistent pollutants because of their high lipophilicity, very limited biotransformation, and slow depuration. Our findings are in agreement with these elements with a time- and dose-dependent increase in PCBs concentration in fish bodies (Anderson et al., 2001)

No steady-state was achieved for any concentration during the exposure time. The uptake curves observed in this experiment were typical of those observed by other authors during bioaccumulation studies of hydrophobic contaminants in fish (Fisk et al., 1998 ; Tomy et al., 2004). Concentration in fish is directly related to the concentration in diets. During the first 90 days of contamination, CB153 concentration in male and female follows a similar kinetic. After this time point, there was a clear differentiation in contamination levels between males and females. For females with the lowest CB153 concentration (identified immediately after spawning), this level was similar to that of males whereas some females had CB153 concentrations four- to fivefold higher than in males. Differences between females may be 
related to the expulsion of PCBs during spawning as we found some PCBs in eggs at a concentration that correlated with the level in females. However, the quantity of PCBs contained in a spawn cannot account for the difference between heavily contaminated females and females which have spawned. It should nevertheless be noted that in a tank, competition exists between females and dominance can greatly reduce the number of spawning females (Gerlach, 2006). It is thus possible that heavily contaminated females are dominated females with a low number of spawns and thus reduced expulsion of PCBs.

Several studies have already been performed to establish the physiological consequences of exposure of zebrafish to PCB among other fish. However, in many cases only one congener is studied while PCBs always occur as mixtures in the wild, in addition doses and/or exposure route may not be relevant. All of these data are very useful to understand the mechanisms underlying possible effects of exposure to PCBs but they may not reflect what happens in an environment contaminated with PCBs. The composition of the mixtures that we have used has been designed to closely mimic some environmental situations in a biological matrix respecting relative proportions of each congener (Antunes et al., 2007 ; Bodiguel et al., 2009 ; Muir et al., 2003) and concentrations have been chosen to reflect the actual concentration in medium and heavily contaminated areas (respectively Loire and Seine estuaries).

Recruitment is the ability of an embryo or a fish to participate in the production of next generation. This includes the ability of an embryo to reach adulthood, and for the adult, the ability to produce gametes suitable for reproduction in terms of quantity and quality. In the present study, we investigated several endpoints related to recruitment including survival of larvae produced by adults exposed to PCBs, egg production, and fertilization rates. For these reasons, we have monitored endpoints which may potentially account for the ability of fish to participate in recruitment using a model species.

There were no differences in the global physiological parameters that we measured including, survival, growth, and organ weight. These results clearly differ from those reported by Örn and colleagues (1998) who found an increase in mortality and a reduction of body weight, LSI, and GSI in their intermediate- and high-dose groups. As mentioned above, the authors used an equivalent dose of the twenty chosen congeners with $80 \mathrm{ng} / \mathrm{g}$ food for the intermediate dose and 400ng/g of highly toxic co-planar congeners 126 and 169 (Örn et al., 1998), which are absent from the mixture that we used. It has also been reported that survival is reduced following direct aqueous exposure of summer flounder larvae to CB126 congeners (Soffientino et al., 2010). Co-planar effects are thought to be mediated by AhR and therefore may elicit a dioxin wasting syndrome which includes weight loss and sometimes death (Walker and Peterson, 1994). However, in some cases, exposure to PCB promote growth; this has been observed after long-term exposure to food dosed with Clophen A50 (Bengtsson, 1980). Increase of growth has also been described in zebrafish exposed to mixtures of POP including DDT and PBDEs in addition to PCBs (Lyche et al., 2010 ; Nourizadeh-Lillabadi et al., 2009). Our results nevertheless agree with those demonstrating an absence of correlation between fish growth and the load of PCBs in wild fish (Bodiguel et al., 2009 ; Rypel and Bayne, 2010) or experimental models (Loizeau et al., in preparation). Mortality and growth alteration thus appear to be induced in fish after exposure to co-planar PCBs congeners, in particular CB126.

PCBs have been reported to disrupt endocrine activity in fish and other vertebrates including humans (Crain et al., 2008 ; Mendola et al., 2008 ; Mills and Chichester, 2005). This has been demonstrated at the molecular level (e.g. hormone or genes expression levels), the cellular level, in organs (e.g. gametes properties or GSI), and individuals (e.g. spawning events, embryo development). To gain insights into the mechanisms underlying alterations in 
reproduction after exposure to PCBs, and to evaluate the functional consequences of this exposure, several endpoints were monitored.

No embryonic deformities or changes in larval survival rates were observed after exposure of parents to PCBs. Again, it appears that the effects depend upon the congeners studied. Several studies report alterations of fish embryonic development or survival after exposure to PCBs. This is the case of exposure to Aroclor 1254 or CB126 which cause general embryotoxicity (McCarthy et al., 2003), alterations in embryonic growth (Na et al., 2009), and changes in heart development (Grimes et al., 2008). Exposure to individual congeners, such as CB126 or CB77, can reduce fish-embryo survival (Foekema et al., 2008 ; Grimes et al., 2008 ; Monosson et al., 1994 ; Soffientino et al., 2010). This has also been demonstrated after exposures to complex mixtures (Örn et al., 1998). However, as mentioned above, CB126 and CB169 in this study were present at high levels. In contrast, exposure to PCB-48 technical mixture, which among other PCBs contains high levels of CB77, did not alter larval survival rate at 10 days post-hatching (Nakayama et al., 2005b). Alterations in survival have been reported with other congeners or mixtures for zebrafish embryos after intraperitoneal injection of females with $1 \mu \mathrm{mol} \mathrm{kg}-1$ CB60, 104, and 190 (Olsson et al., 1999) and for minnow embryos after exposure to Clophen A50 (Bengtsson, 1980).

We conclude that the PCBs mixture that was used in the present study has no effect on egg development and viability either through egg quality or embryonic development. The deleterious effects reported in other studies are mainly due to the use of coplanar dioxin-like congeners.

We observed alterations in ovary structure in both contaminated groups with a dose effect. Indeed, there was a decrease in the proportion of stage 2 to 4 follicles in PCB-Medium female ovaries and in a six out of ten PCB-High female ovaries. This phenotype gets worse for the remaining PCB-High females with the absence of maturing stage 3 and 4 oocytes. These phenotypes are associated with an increase of atretic follicles in females fed both contaminated diets. These observations agree with previous reports of increased in atretic follicles after exposure to PCBs (Cross and Jo Ellen, 1988) and a bias towards primary follicles (Örn et al., 1998). It is to note that exposures presented here began after sex determination but overlap with differentiation of both sex gonads (Orban et al., 2009). However, the present study is the first report of such ovary anomalies after exposure to a mixture of PCBs mimicking some environmental situations. Our approach is thus suitable to investigate mechanisms underlying the alterations in ovary function that occur in polluted environments.

At the functional level, we observed a significant reduction of the overall fertilization rate. This was not due to a reduction of fertilization of each spawn but instead to an increase in the number of poorly fertilized spawns at the expense of highly fertilized ones. To our knowledge, this is the first report that a mixture of PCBs mimicking some environmental situations can decrease the fertilization rate of fish spawns. Our study revealed that, irrespective of the sex of the contaminated fish, a strong decrease of fertilization rate is observed with a non-additional effect when both males and females are contaminated. Alteration of fertility has already been reported for several vertebrate species (Letcher et al., 2010 ; Pocar et al., 2006). Reduction of fertility has also been described for oocytes directly incubated in PCBs and then submitted to in vitro fertilization (Campagna et al., 2001 ; Kholkute et al., 1994). Several mechanisms could underlie this reduction. There may be alterations in oocyte competence (Krogenaes et al., 1998), or sperm quality or release. We did not observe gross alterations of testes structure, but sperm defects appear to be more related to sperm properties (Hauser et al., 2003 ; Njiwa et al., 2004 ; Richthoff et al., 2003). Fertilization and/or sperm release defects can also be due to alterations in male reproductive behavior (Njiwa et al., 2004). The absence of additive effects of female and male alterations 
on the fertilization rate is puzzling. However, several reports have shown that PCBs can act as both oestrogenic and anti-oestrogenic depending on their chlorination level (Pliskova et al., 2005).

In summary, our study shows that PCBs mixtures representatives of some environmental situations may lead to changes in the reproduction abilities of fish that may impair recruitment and population stability. It is possible that much of these observations are due to non dioxin-like congeners contained in the diet. Additional experiments should be performed to clarify this point. Several other questions remain unanswered, in particular concerning the timing of structural damage to the ovaries and the mechanisms underlying alteration in fertilization rate for both females and males.

\section{Conclusions}

Our data indicate that exposing zebrafish to mixtures of PCBs through diet leads to contamination of fish with a clear bioaccumulation and a transfer from adult females to eggs.

In terms of physiology, we observed alterations of ovary structure with an increase of atresia which can be related to a decrease in the number of eggs per spawn and fertilization. This can be combined with a decrease in the number of spawn per female. These findings indicate that, despite starting breeding under ideal conditions for reproduction, an exposure to mixtures of PCBs mimicking some environmental situations including mainly non dioxinlike congeners can lead to a dramatic reduction in the number of offspring produced by a female over a lifetime. This is of great concern for wild species living in natural conditions. More studies are needed to identify the mechanisms underlying these observations and a new series of exposures is currently underway.

\section{Acknowledgments}

We thank Marie-Laure Bégout for valuable comments on the manuscript, and Didier Leguay for laboratory assistance. This study was supported by the Conseil Général de Charente maritime (PhD fellowship for TD) and EC2CO-Cytrix (grant GénérationPOP to XC).

\section{References}

Andersson, P.L., Berg, A.H., Bjerselius, R., Norrgren, L., Olsén, H., Olsson, P.E., Örn, S., Tysklind, M., 2001. Bioaccumulation of selected PCBs in zebrafish, three-spined stickleback, and arctic char after three different routes of exposure. Archives of Environmental Contamination and Toxicology 40, 519-530.

Antunes, P., Amado, J., Vale, C., Gil, O., 2007. Influence of the chemical structure on mobility of PCB congeners in female and male sardine (Sardina pilchardus) from Portuguese coast. Chemosphere 69, 395-402.

Bengtsson, B.-E., 1980. Long-term effects of PCB (Clophen A50) on growth, reproduction and swimming performance in the Minnow, Phoxinus Phoxinus. Water Research 14, 681687. 
Billsson, K., Westerlund, L., Tysklind, M., Olsson, P.-E., 1998. Developmental disturbances caused by polychlorinated biphenyls in zebrafish (Brachydanio rerio). Marine Environmental Research 46, 461-464.

Bodiguel, X., Loizeau, V., Le Guellec, A.M., Roupsard, F., Philippon, X., Mellon-Duval, C., 2009. Influence of sex, maturity and reproduction on PCB and p,p'DDE concentrations and repartitions in the European hake (Merluccius merluccius, L.) from the Gulf of Lions (N.W. Mediterranean). Sci Total Environ 408, 304-311.

Borgå, K., Gabrielsen, G.W., Skaare, J.U., 2001. Biomagnification of organochlorines along a Barents Sea food chain. Environmental Pollution (Barking, Essex: 1987) 113, 187-198.

Breivik, K., Sweetman, A., Pacyna, J.M., Jones, K.C., 2002. Towards a global historical emission inventory for selected PCB congeners--a mass balance approach. 1. Global production and consumption. Sci Total Environ 290, 181-198.

Campagna, C., Sirard, M.A., Ayotte, P., Bailey, J.L., 2001. Impaired maturation, fertilization, and embryonic development of porcine oocytes following exposure to an environmentally relevant organochlorine mixture. Biol Reprod 65, 554-560.

Crain, D.A., Janssen, S.J., Edwards, T.M., Heindel, J., Ho, S.-m., Hunt, P., Iguchi, T., Juul, A., McLachlan, J.A., Schwartz, J., Skakkebaek, N., Soto, A.M., Swan, S., Walker, C., Woodruff, T.K., Woodruff, T.J., Giudice, L.C., Guillette Jr, L.J., 2008. Female reproductive disorders: the roles of endocrine-disrupting compounds and developmental timing. Fertility and Sterility 90, 911-940.

Cross, J.N., Jo Ellen, H., 1988. Evidence for impaired reproduction in white croaker (Genyonemus lineatus) from contaminated areas off Southern California. Marine Environmental Research 24, 185-188.

Fisk, A.T., Hobson, K.A., Norstrom, R.J., 2001. Influence of chemical and biological factors on trophic transfer of persistent organic pollutants in the northwater polynya marine food web. Environmental Science \& Technology 35, 732-738.

Fisk, A.T., Norstrom, R.J., Cymbalisty, C.D., Muir, D.C.G., 1998. Dietary accumulation and depuration of hydrophobic organochlorines: Bioaccumulation parameters and their relationship with the octanol/water partition coefficient. Environmental Toxicology and Chemistry 17, 951-961.

Foekema, E.M., Deerenberg, C.M., Murk, A.J., 2008. Prolonged ELS test with the marine flatfish sole (Solea solea) shows delayed toxic effects of previous exposure to PCB 126. Aquatic Toxicology 90, 197-203.

Gerlach, G., 2006. Pheromonal regulation of reproductive success in female zebrafish: female suppression and male enhancement. Animal Behaviour 72, 1119-1124.

Grimes, A.C., Erwin, K.N., Stadt, H.A., Hunter, G.L., Gefroh, H.A., Tsai, H.-J., Kirby, M.L., 2008. PCB126 Exposure Disrupts ZebraFish Ventricular and Branchial but Not Early Neural Crest Development. Toxicological Sciences 106, 193-205.

Hauser, R., Chen, Z., Pothier, L., Ryan, L., Altshul, L., 2003. The relationship between human semen parameters and environmental exposure to polychlorinated biphenyls and p,p'-DDE. Environ Health Perspect 111, 1505-1511.

Hill, A.J., Teraoka, H., Heideman, W., Peterson, R.E., 2005. Zebrafish as a model vertebrate for investigating chemical toxicity. Toxicol Sci 86, 6-19.

Hinton, D.E., Kullman, S.W., Hardman, R.C., Volz, D.C., Chen, P.-J., Carney, M., Bencic, D.C., 2005. Resolving mechanisms of toxicity while pursuing ecotoxicological relevance? Marine Pollution Bulletin 51, 635-648.

Jaouen-Madoulet, A., Abarnou, A., Le Guellec, A.M., Loizeau, V., Leboulenger, F., 2000. Validation of an analytical procedure for polychlorinated biphenyls, coplanar polychlorinated biphenyls and polycyclic aromatic hydrocarbons in environmental samples. Journal of Chromatography A 886, 153-173.

Johansen, H.R., Alexander, J., Rossland, O.J., Planting, S., Lovik, M., Gaarder, P.I., Gdynia, W., Bjerve, K.S., Becher, G., 1996. PCDDs, PCDFs, and PCBs in human blood in relation to consumption of crabs from a contaminated Fjord area in Norway. Environ Health Perspect $104,756-764$. 
Kholkute, S.D., Rodriguez, J., Dukelow, W.R., 1994. Reproductive toxicity of Aroclor-1254: effects on oocyte, spermatozoa, in vitro fertilization, and embryo development in the mouse. Reprod Toxicol 8, 487-493.

Koç, N.D., Aytekin, Y., Yüce, R., 2008. Ovary maturatıon stages and histological investigation of ovary of the Zebrafish (Danio rerio). Braz. arch. biol. technol. 51, 513-522.

Krogenaes, A.K., Nafstad, I., Skare, J.U., Farstad, W., Hafne, A.L., 1998. In vitro reproductive toxicity of polychlorinated biphenyl congeners 153 and 126 . Reprod Toxicol 12, 575-580.

Lawrence, C., 2007. The husbandry of zebrafish (Danio rerio): A review. Aquaculture 269, 120.

Letcher, R.J., Bustnes, J.O., Dietz, R., Jenssen, B.M., Jørgensen, E.H., Sonne, C., Verreault, J., Vijayan, M.M., Gabrielsen, G.W., 2010. Exposure and effects assessment of persistent organohalogen contaminants in arctic wildlife and fish. Science of The Total Environment 408, 2995-3043.

Lyche, J.L., Nourizadeh-Lillabadi, R., Almaas, C., Stavik, B., Berg, V., Skare, J.U., Alestrom, P., Ropstad, E., 2010. Natural mixtures of persistent organic pollutants (POP) increase weight gain, advance puberty, and induce changes in gene expression associated with steroid hormones and obesity in female zebrafish. J Toxicol Environ Health A 73, 1032-1057. McCarthy, I.D., Fuiman, L.A., Alvarez, M.C., 2003. Aroclor 1254 affects growth and survival skills of Atlantic croaker Micropogonias undulatus larvae. Marine Ecology Progress Series 252, 295-301.

McFarland, V.A., Clarke, J.U., 1989. Environmental occurrence, abundance, and potential toxicity of polychlorinated biphenyl congeners: considerations for a congener-specific analysis. Environmental Health Perspectives 81, 225-239.

Mendola, P., Messer, L.C., Rappazzo, K., 2008. Science linking environmental contaminant exposures with fertility and reproductive health impacts in the adult female. Fertility and Sterility 89, e81-e94.

Mills, L.J., Chichester, C., 2005. Review of evidence: Are endocrine-disrupting chemicals in the aquatic environment impacting fish populations? Science of The Total Environment 343, $1-34$.

Monosson, E., 1999/2000. Reproductive and developmental effects of PCBs in fish: a summary of laboratory and field studies. Reviews in Toxicology 3, 25-75.

Monosson, E., James Fleming, W., Sullivan, C.V., 1994. Effects of the planar PCB 3,3',4,4'tetrachlorobiphenyl (TCB) on ovarian development, plasma levels of sex steroid hormones and vitellogenin, and progeny survival in the white perch (Morone americana). Aquatic Toxicology 29, 1-19.

Muir, D., Savinova, T., Savinov, V., Alexeeva, L., Potelov, V., Svetochev, V., 2003. Bioaccumulation of PCBs and chlorinated pesticides in seals, fishes and invertebrates from the White Sea, Russia. The Science of The Total Environment 306, 111-131.

Na, Y.R., Seok, S.H., Baek, M.W., Lee, H.Y., Kim, D.J., Park, S.H., Lee, H.K., Park, J.H., 2009. Protective effects of vitamin $E$ against 3,3',4,4',5-pentachlorobiphenyl (PCB126) induced toxicity in zebrafish embryos. Ecotoxicol Environ Saf 72, 714-719.

Nakayama, K., Oshima, Y., Hiramatsu, K., Honjo, T., 2004. Alteration of general behavior of male medaka, Oryzias latipes, exposed to tributyltin and/or polychlorinated biphenyls. Journal of Faculty of Agriculture, Kyushu University 49, 85-92.

Nakayama, K., Oshima, Y., Hiramatsu, K., Shimasaki, Y., Honjo, T., 2005a. Effects of Polychlorinated Biphenyls on the schooling behavior of japanese medaka (Oryzias latipes). Environmental Toxicology and Chemistry 24, 2588-2593.

Nakayama, K., Oshima, Y., Nagafuchi, K., Hano, T., Shimasaki, Y., Honjo, T., 2005b. Earlylife-stage toxicity in offspring from exposed parent medaka, Oryzias latipes, to mixtures of tributyltin and polychlorinated biphenyls. Environ Toxicol Chem 24, 591-596.

Nfon, E., Cousins, I.T., 2006. Interpreting time trends and biomagnification of PCBs in the Baltic region using the equilibrium lipid partitioning approach. Environmental Pollution (Barking, Essex: 1987) 144, 994-1000. 
Njiwa, J.R.K.J.R.K., Müller, P., Klein, R., 2004. Binary mixture of DDT and Arochlor1254: effects on sperm release by Danio rerio. Ecotoxicology and Environmental Safety 58, 211219.

Nourizadeh-Lillabadi, R., Lyche, J.L., Almaas, C., Stavik, B., Moe, S.J., Aleksandersen, M., Berg, V., Jakobsen, K.S., Stenseth, N.C., Skåre, J.U., Alestrøm, P., Ropstad, E., 2009. Transcriptional regulation in liver and testis associated with developmental and reproductive effects in male zebrafish exposed to natural mixtures of persistent organic pollutants (POP). Journal of Toxicology and Environmental Health. Part A 72, 112-130.

Nyman, M., Koistinen, J., Fant, M.L., Vartiainen, T., Helle, E., 2002. Current levels of DDT, PCB and trace elements in the Baltic ringed seals (Phoca hispida baltica) and grey seals (Halichoerus grypus). Environ Pollut 119, 399-412.

Olsson, P.-E., Westerlund, L., Teh, S.J., Billsson, K., Berg, A.H.k., Tysklind, M., Nilsson, J., Eriksson, L.-O., Hinton, D.E., 1999. Effects of Maternal Exposure to Estrogen and PCB on Different Life Stages of Zebrafish (Danio rerio). Ambio 28, 100-106.

Orban, L., Sreenivasan, R., Olsson, P.-E., 2009. Long and winding roads: Testis differentiation in zebrafish. Molecular and Cellular Endocrinology 312, 35-41.

Örn, S., Andersson, P.L., Förlin, L., Tysklind, M., Norrgren, L., 1998. The impact on reproduction of an orally administered mixture of selected PCBs in zebrafish (Danio rerio). Archives of Environmental Contamination and Toxicology 35, 52-57.

Pliskova, M., Vondracek, J., Canton, R.F., Nera, J., Kocan, A., Petrik, J., Trnovec, T., Sanderson, T., van den Berg, M., Machala, M., 2005. Impact of polychlorinated biphenyls contamination on estrogenic activity in human male serum. Environ Health Perspect 113, 1277-1284.

Pocar, P., Brevini, T.A.L., Antonini, S., Gandolfi, F., 2006. Cellular and molecular mechanisms mediating the effect of polychlorinated biphenyls on oocyte in vitro maturation. Reproductive Toxicology (Elmsford, N.Y.) 22, 242-249.

Pompa, G., Caloni, F., Fracchiolla, M.L., 2003. Dioxin and PCB contamination of fish and shellfish: assessment of human exposure. Review of the international situation. Vet Res Commun 27 Suppl 1, 159-167.

Richthoff, J., Rylander, L., Jonsson, B.A., Akesson, H., Hagmar, L., Nilsson-Ehle, P., Stridsberg, M., Giwercman, A., 2003. Serum levels of 2,2',4,4',5,5'-hexachlorobiphenyl (CB153 ) in relation to markers of reproductive function in young males from the general Swedish population. Environ Health Perspect 111, 409-413.

Ross, G., 2004. The public health implications of polychlorinated biphenyls (PCBs) in the environment. Ecotoxicology and Environmental Safety 59, 275-291.

Rypel, A.L., Bayne, D.R., 2010. Do fish growth rates correlate with PCB body burdens? Environ Pollut 158, 2533-2536.

Safe, S., 2005. Clinical correlates of environmental endocrine disruptors. Trends in Endocrinology and Metabolism 16, 139-144.

Schantz, M.M., Parris, R.M., Kurz, J., Ballschmiter, K., Wise, S.A., 1993. Comparison of methods for the gas-chromatographic determination of PCB congeners and chlorinated pesticides in marine reference materials. Fresenius' Journal of Analytical Chemistry 346, 766-778-778.

Schell, L.M., Gallo, M.V., 2010. Relationships of putative endocrine disruptors to human sexual maturation and thyroid activity in youth. Physiol Behav 99, 246-253.

Schulz, R.W., de Franca, L.R., Lareyre, J.J., Le Gac, F., Chiarini-Garcia, H., Nobrega, R.H., Miura, T., 2010. Spermatogenesis in fish. Gen Comp Endocrinol 165, 390-411.

Soffientino, B., Nacci, D.E., Specker, J.L., 2010. Effects of the dioxin-like PCB 126 on larval summer flounder (Paralichthys dentatus). Comp Biochem Physiol C Toxicol Pharmacol 152, 9-17.

Spitsbergen, J.M., Kent, M.L., 2003. The State of the Art of the Zebrafish Model for Toxicology and Toxicologic Pathology Research--Advantages and Current Limitations. Toxicologic Pathology 31, 62-87.

Spitsbergen, J.M., Tsai, H.-W., Reddy, A., Miller, T., Arbogast, D., Hendricks, J.D., Bailey, G.S., 2000. Neoplasia in Zebrafish (Danio rerio) Treated with 7,12- 
Diniethylbenz[a]anthracene by Two Exposure Routes at Different Developmental Stages. Toxicologic Pathology 28, 705-715.

Tomy, G.T., Palace, V.P., Halldorson, T., Braekevelt, E., Danell, R., Wautier, K., Evans, B., Brinkworth, L., Fisk, A.T., 2004. Bioaccumulation, biotransformation, and biochemical effects of brominated diphenyl ethers in juvenile lake trout (Salvelinus namaycush). Environ Sci Technol 38, 1496-1504.

van Ginneken, V., Palstra, A., Leonards, P., Nieveen, M., van den Berg, H., Flik, G., Spanings, T., Niemantsverdriet, P., van den Thillart, G., Murk, A., 2009. PCBs and the energy cost of migration in the European eel (Anguilla anguilla L.). Aquatic Toxicology 92, 213-220.

Walker, M.K., Peterson, R.E., 1994. Aquatic toxicity of dioxins and related chemicals., in: Schecter, A. (Ed.), Dioxins and health. Plenum Press, New York, USA pp. 333-374.

Westerlund, L., Billsson, K., Andersson, P.L., Tysklind, M., Olsson, P.-E., 2000. Early lifestage mortality in zebrafish (Danio rerio) following maternal exposure to polychlorinated biphenyls and estrogen. Environmental Toxicology and Chemistry 19, 1582-1588.

\section{Tables}

Table 1. Diets composition. List of PCBs congeners used in this work along with the chlorine number. Target and measured PCBs concentrations in PCB-medium and PCB-high diets are indicated (mean $\pm \mathrm{SD}$ ). Reference congener CB153 is indicated in bold.

\begin{tabular}{|c|c|c|c|c|c|}
\hline \multirow[b]{2}{*}{ Congeners } & \multirow[b]{2}{*}{$\begin{array}{l}\text { Chlorine } \\
\text { number }\end{array}$} & \multicolumn{2}{|c|}{ PCB-medium diet } & \multicolumn{2}{|l|}{ PCB-high diet } \\
\hline & & $\begin{array}{l}\text { Targeted } \\
\text { concentration } \\
(\mathrm{ng} / \mathrm{g})\end{array}$ & $\begin{array}{l}\text { Measured } \\
\text { concentration } \\
(\mathrm{ng} / \mathrm{g})\end{array}$ & $\begin{array}{l}\text { Targeted } \\
\text { concentration } \\
(\mathrm{ng} / \mathrm{g})\end{array}$ & $\begin{array}{l}\text { Measured } \\
\text { concentration } \\
(\mathrm{ng} / \mathrm{g})\end{array}$ \\
\hline CB28 & 3 & 10 & $4.8 \pm 0.6$ & 50 & $16 \pm 3.3$ \\
\hline CB52 & 4 & 25 & $20 \pm 0.8$ & 125 & $82 \pm 11.5$ \\
\hline CB101 & 5 & 50 & $45 \pm 2.3$ & 250 & $191 \pm 9.5$ \\
\hline CB149 & 6 & 50 & $47 \pm 4.9$ & 250 & $217 \pm 11.6$ \\
\hline CB118 & 5 & 50 & $54 \pm 4.4$ & 250 & $207 \pm 7.9$ \\
\hline CB153 & 6 & 100 & $106 \pm 5.5$ & 500 & $420 \pm 15$ \\
\hline CB132 & 6 & 25 & $18 \pm 0.9$ & 125 & $104 \pm 5$ \\
\hline CB105 & 5 & 25 & $26 \pm 5.3$ & 125 & $133 \pm 19.5$ \\
\hline CB138 & 6 & 100 & $99 \pm 4.9$ & 500 & $431 \pm 16.4$ \\
\hline CB156 & 6 & 25 & $17 \pm 1.5$ & 125 & $113 \pm 4$ \\
\hline CB180 & 7 & 50 & $43 \pm 2.1$ & 250 & $215 \pm 4.5$ \\
\hline CB170 & 7 & 25 & $26 \pm 1.6$ & 125 & $126 \pm 4.5$ \\
\hline CB194 & 8 & 10 & $9 \pm 1.1$ & 50 & $47 \pm 1.7$ \\
\hline
\end{tabular}


Table 2. Biometry and survival among different groups. Initial and final weight and mean SGR over the period for male and female and survival rate for both sex exposed to control feeds or PCB diets, measured after 247 days of exposure (mean \pm SD). There is no significant difference between groups.

\begin{tabular}{|c|c|c|c|c|c|c|}
\hline Dose group & $\begin{array}{l}\text { Initial } \\
\text { weight }\end{array}$ & $\begin{array}{l}\text { Final } \\
\text { weight } \\
\text { male }(\mathrm{mg})\end{array}$ & SGR male & $\begin{array}{l}\text { Final weight } \\
\text { female (mg) }\end{array}$ & $\begin{array}{l}\text { SGR } \\
\text { female }\end{array}$ & $\begin{array}{l}\text { Survival } \\
\text { rate (\%) }\end{array}$ \\
\hline Plain & $196 \pm 81$ & $641 \pm 70$ & $0.33 \pm 0.5$ & $929 \pm 219$ & $0.62 \pm 0.45$ & $69.6 \pm 21.9$ \\
\hline Solvent & $224 \pm 75$ & $594 \pm 94$ & $0.42 \pm 0.2$ & $1008 \pm 200$ & $0.54 \pm 0.64$ & $56.9 \pm 13.7$ \\
\hline PCB-medium & $215 \pm 83$ & $623 \pm 117$ & $0.35 \pm 0.44$ & $1036 \pm 251$ & $0.67 \pm 0.74$ & $78.9 \pm 13.9$ \\
\hline PCB-high & $217 \pm 82$ & $598 \pm 136$ & $0.42 \pm 0.6$ & $1030 \pm 287$ & $0.63 \pm 0.71$ & $64.8 \pm 12.3$ \\
\hline
\end{tabular}

Table 3. Organs biometry. Mean liver somatic index (LSI) and gonad somatic index (GSI) measured after 247 days of exposure for female ( \pm SEM). There is no significant difference between groups.

\begin{tabular}{|c|c|c|c|}
\hline Dose group & Fish $(n)$ & LSI & GSI \\
\hline Plain & 9 & $2.29 \pm 0.22$ & $14.22 \pm 1.17$ \\
\hline Solvent & 8 & $3.16 \pm 0.27$ & $15.39 \pm 2.24$ \\
\hline PCB-medium & 10 & $3.09 \pm 0.29$ & $17.75 \pm 1.84$ \\
\hline PCB-high & 11 & $2.56 \pm 0.28$ & $14.00 \pm 1.42$ \\
\hline
\end{tabular}

Table 4. Spawn characteristics. Mean of spawning onset, total size of spawn, number of fertilized eggs per spawns and calculated mean fertilization rate obtained from adults exposed to control or PCB diets. The number in parenthesis after the spawning onset value indicates the number of tanks considered (mean \pm SEM; * $p<0.05$ ).

\begin{tabular}{|c|c|c|c|c|c|}
\hline Dose group & $\begin{array}{l}\text { Spawning onset } \\
\text { (days) }\end{array}$ & $\begin{array}{l}\text { Spawns } \\
(n)\end{array}$ & $\begin{array}{l}\text { Number of } \\
\text { eggs }\end{array}$ & $\begin{array}{l}\text { Number of } \\
\text { fertilized eggs }\end{array}$ & $\begin{array}{l}\text { Fertilization } \\
\text { rate }(\%)\end{array}$ \\
\hline Plain & $126.7 \pm 1.2(3)$ & 23 & $408.4 \pm 43.1$ & $317.3 \pm 38.6$ & $80.7 \pm 6.3$ \\
\hline Solvent & $73.7 \pm 25.7(3)$ & 48 & $422.6 \pm 36.9$ & $378.4 \pm 37.5$ & $84.8 \pm 3.9$ \\
\hline PCB-medium & $93.2 \pm 17.5(6)$ & 48 & $434.1 \pm 32.6$ & $277.9 \pm 31.9$ & $62.9 \pm 5.3^{*}$ \\
\hline PCB-high & $109.8 \pm 14.5(6)$ & 41 & $384.6 \pm 38.5$ & $236.2 \pm 34.3^{*}$ & $62.6 \pm 6.0$ * \\
\hline
\end{tabular}




\section{Figures}
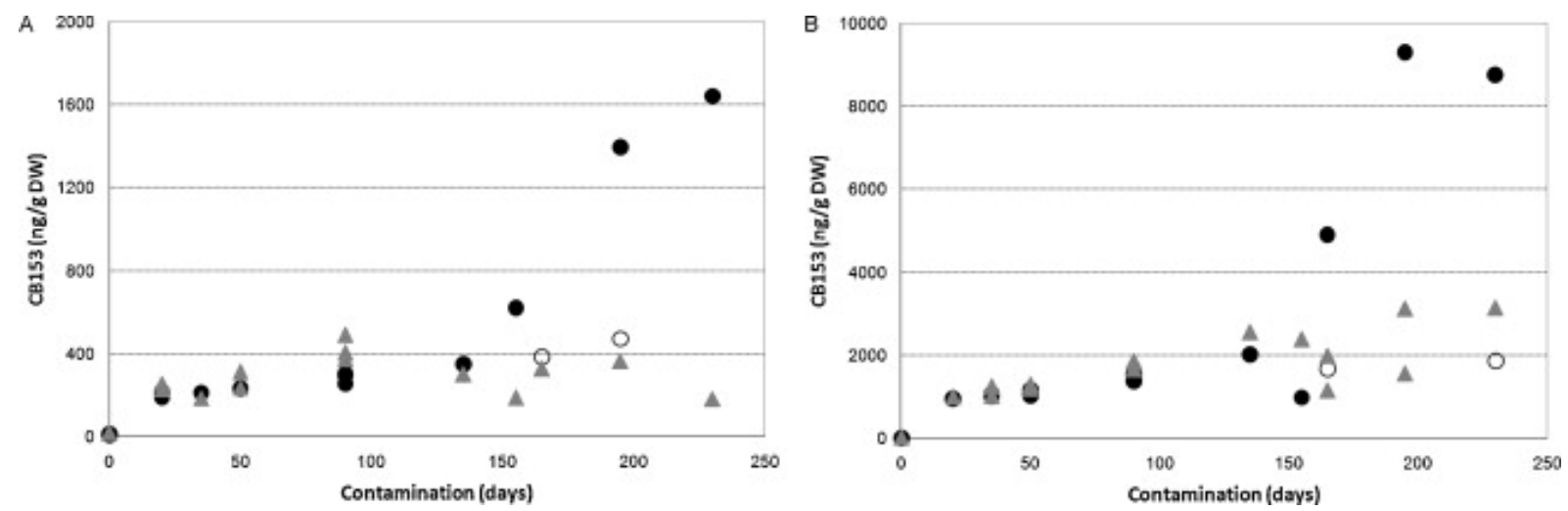

Fig. 1. PCBs concentration in fish over-time. Concentration of CB153 as a representative of all congeners has been determined for males (triangles) and females (filled circles) after exposure to PCB-medium (A), or PCB-high (B) diets. In both cases, concentration of PCBs has also been determined in females just after spawning (empty circles).

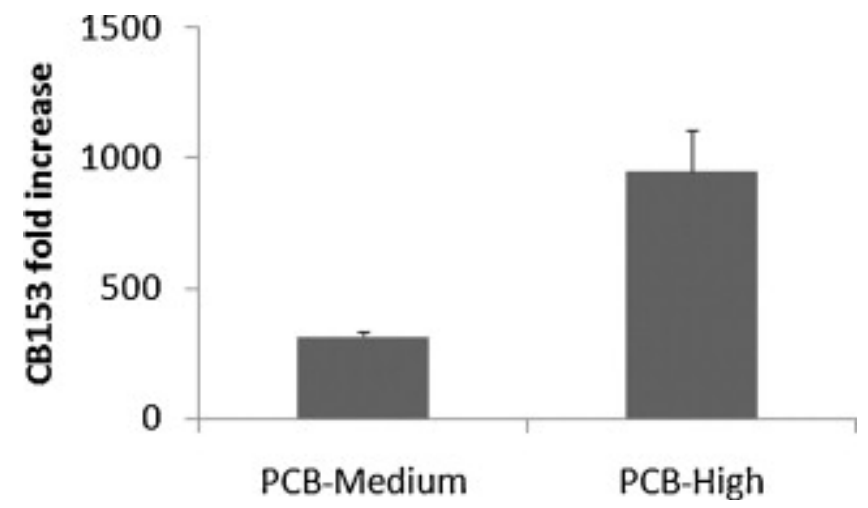

Fig. 2. $P C B$ concentration in eggs. Fold-increase of $C B 153$ concentration in egg spawn by females exposed to PCB-medium and PCB-high diets compared with Solvent diet. 


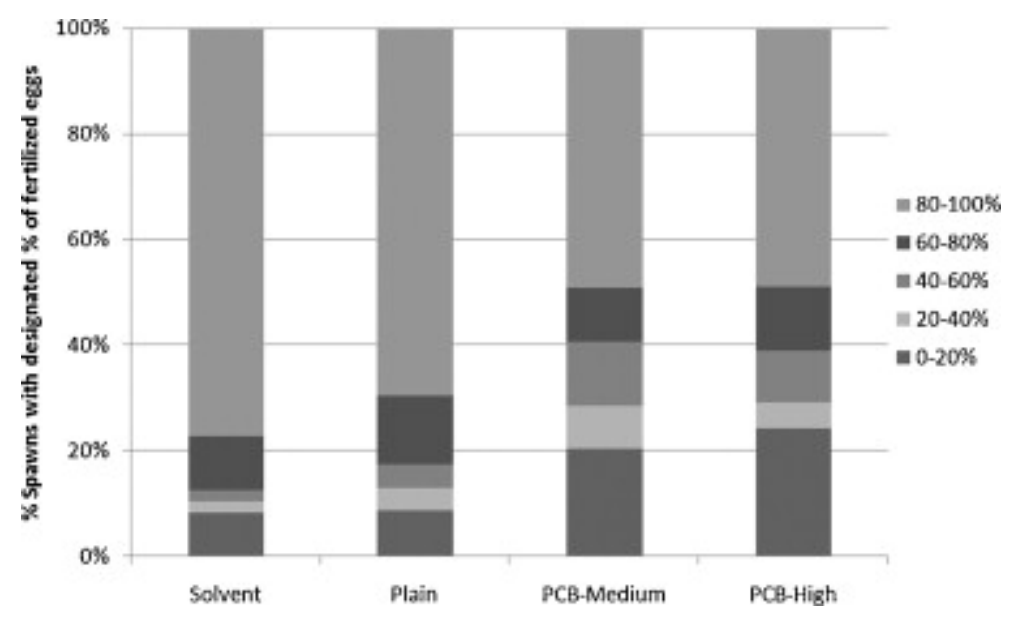

Fig. 3. Spawn quality distribution. Distribution of fertilization rate frequencies obtained from adults exposed to control or PCB diets. Chi-square test indicates that the distributions are different $(p=0.0002)$.
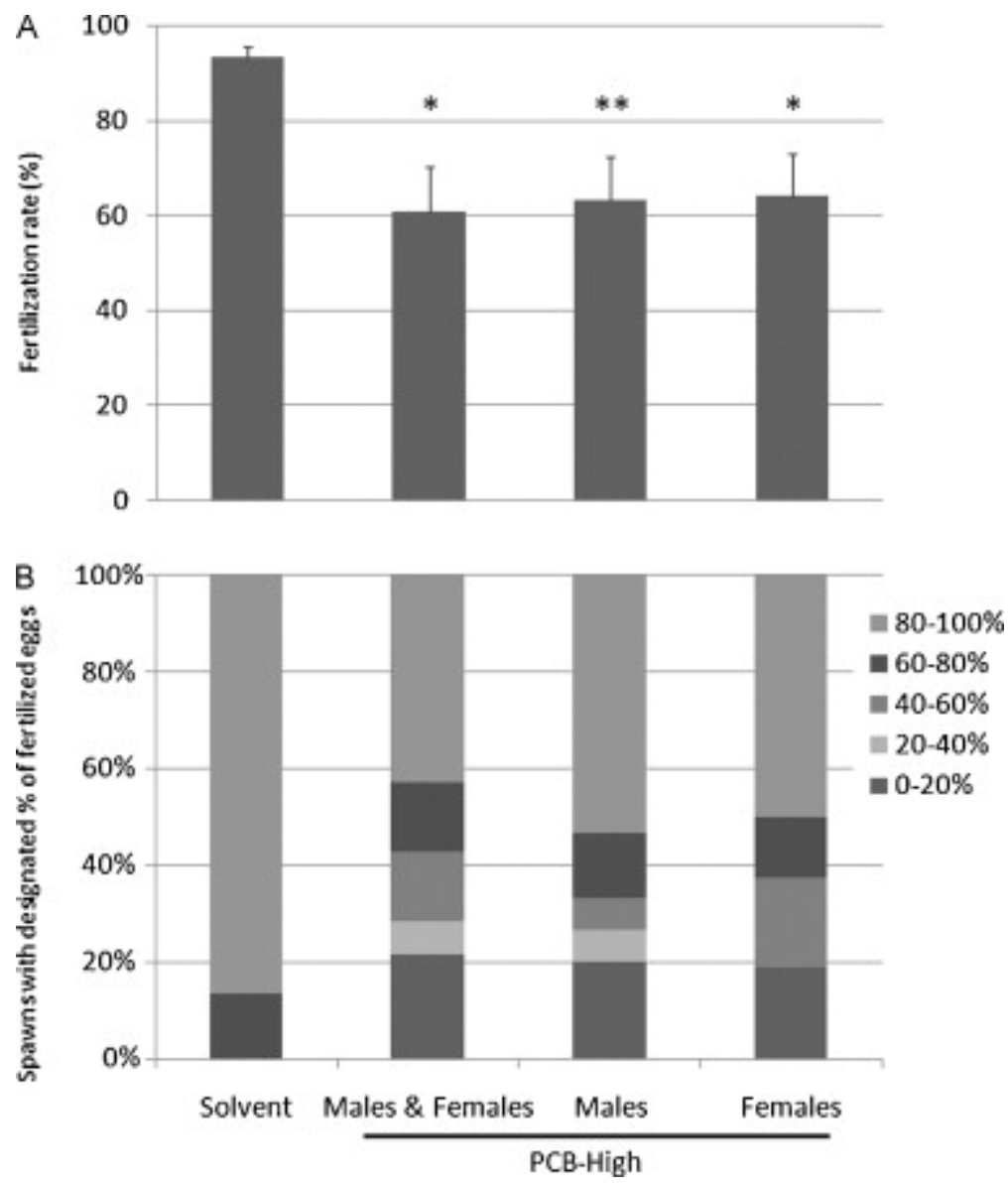

Fig. 4. Spawn quality distribution according to sex of the contaminated fish. (A) Fertilization rate obtained from adults exposed to control or PCB diets. In Solvent group both fish are from the Solvent group ( $n=15$ spawns) while other 3 conditions the sex of fish fed PCB-high is indicated at the bottom of the figure. In the case only one fish has been fed PCB-high diet, the other fish is from Solvent group. Number of spawns are $n=14$ for males and females, $n=15$ for males and $n=16$ for females. (mean \pm SEM; ${ }^{*} p<0.05$; ${ }^{* \star} p<0.01$ ). (B) Percentage of 
spawns with the designated fertilization rate for spawns described above. Chi-square test indicates that the distributions are different $(p<0.0001)$.

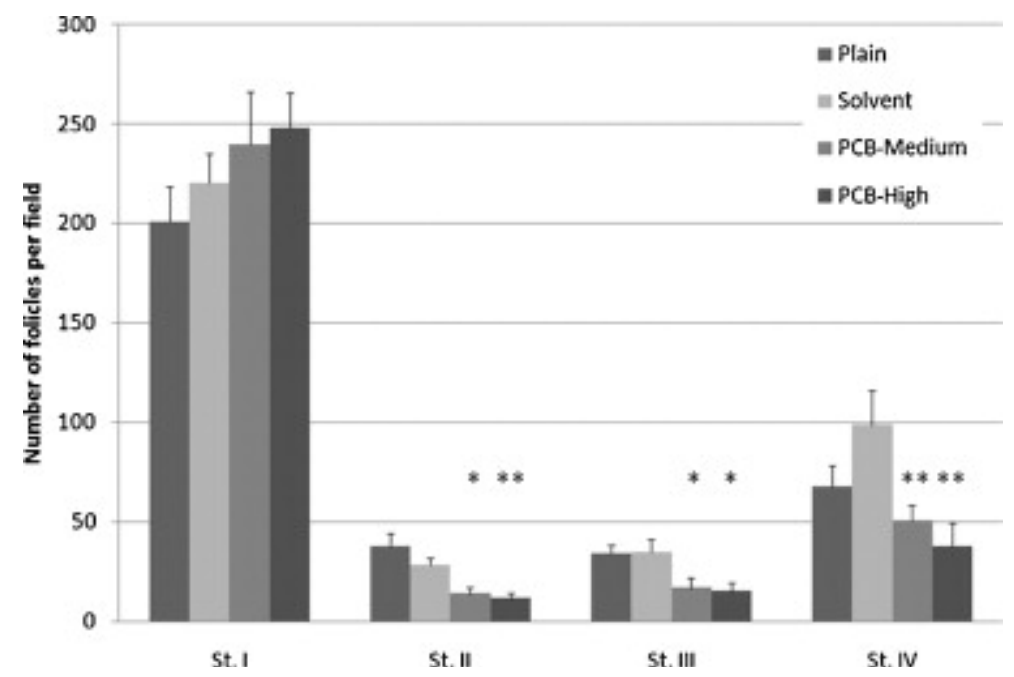

Fig. 5. Follicle stages. Number of different follicles in ovaries of females exposed to control or PCB diets according to their stage. The statistical significance of the differences was calculated for each stage between the different groups using an ANOVA and a PLSD Fisher test $\left({ }^{\star} p<0.05 ;{ }^{*} p<0.01\right)$. 

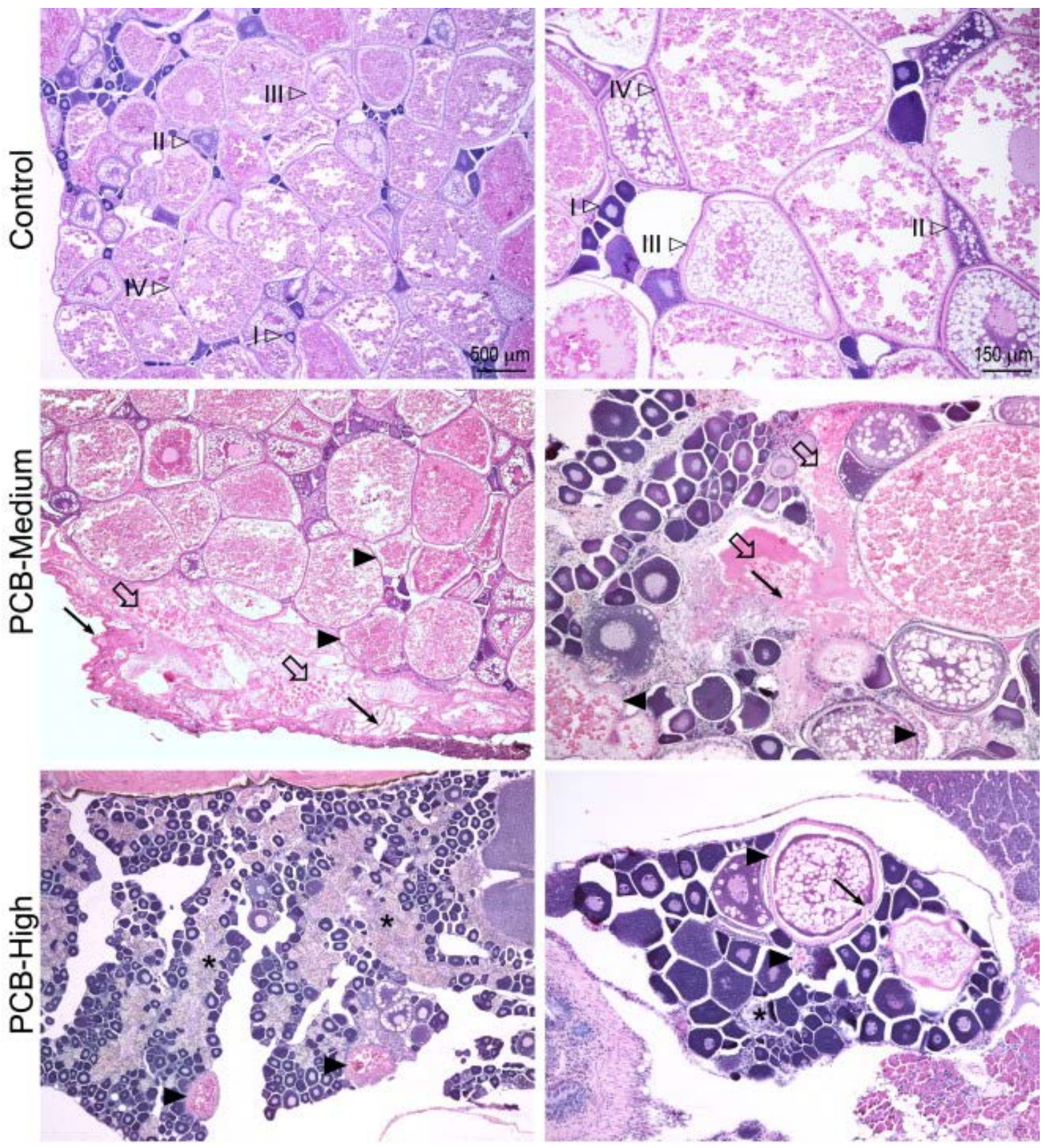

Fig. 6. Histological structure of ovaries. Zebrafish female ovaries stained with HES were photographed at low (left) and medium (right) magnification. The different stages of maturation of ovarian follicles (I-IV) can be identified in the ovary of a control fish (Solvent and Plain). The ovary from fish exposed to PCB-medium diet (middle panel) presents a number of atretic follicles (arrow head) as well as oocyte clusters in which there are fragments of vitelline membrane (full arrow) and yolk granules (open arrow). The number of follicles at stage III (vitellogenic) and stage IV (mature oocyte) is slightly decreased compared with the control. The ovary of fish exposed to PCB-high diet (lower panel) presents an almost complete absence of follicular stages III and IV. A few rare follicles at stage IV are atretic (arrow head) with a vitelline membrane forming characteristic folds (full arrow). Follicular depletion leaves large coalescent areas, corresponding to a granulomatous inflammatory reaction $\left(^{*}\right)$. 